УДК 159.922.2:316.6

DOI: $10.18384 / 2310-7189-2017-2-29-41$

\title{
ПСИХОГЕОГРАФИЯ ГОРОДА
}

\author{
Валишин Ю.И. \\ Московский государственный областной университет \\ 105005, г. Москва, ул. Радио, д.10А, Российская Федерация
}

Аннотация. Статья посвящена проблемам создания эко-полиса и особенностям городской природной среды. Показано целенаправленное формирование экопозитивной городской среды и изменение поведения человека в условиях экополиса. Уделено внимание восприятию городской среды человеком, влиянию этой среды на поведение горожан. Затронут вопрос влияния человека на формирование городской среды, экологию городов. Рассматриваются психологические проблемы, возникающие при взаимодействии человека и городской среды.

Ключевые слова: город, образ жизни, восприятие, психогеография, поведение.

\section{PSYCHOGEOGRAPHY OF THE CITY}

\section{Yu. Valishin \\ Moscow Region State University \\ ul. Radio 10A, 105005 Moscow, Russian Federation}

\begin{abstract}
The paper addresses the problems of creation of an eco-city and considers the features of the urban environment. It is shown how the urban environment is formed. The changes in human behavior under conditions of an eco-city are demonstrated. Attention is paid to the perception of the urban environment by people and the influence of the environment on the behavior of citizens. The issue of human influence on the formation of the urban environment and the ecology of the cities is discussed, and information about the problems arising from the interaction of people and urban environment with psychology is presented.
\end{abstract}

Key words: city, lifestyle, perception, psychogeography, behavior.

Понятие психогеографии появилось в 50-х гг. 20-го столетия. Оно разработано кругом европейских интеллектуалов, которые пытались создать модель исторического изучения городского пространства, выделить ключевые идейные элементы психогеографии и указать точки взаимодействия психогеографии с историей города. Эти исследователи разрабатывали концепцию унитарного урбанизма, под руководством французского философа русского происхождения И. Щеглова. Эта концепция была дополнена исследованиями Г. Дебора и Ш. Бодлера, которые развивали концепцию унитарного урбанизма. Под унитарным урбанизмом понимается синтез искусства и технологии, предусматривающий отказ от евклидовой (классической) архитектуры. При этом само понятие «ар-

๔ Валишин Ю.И., 2017. 
хитектура» определялось И. Щегловым как простой способ артикуляции времени и пространства и моделирования реального воплощения мечты.

Все эти интеллектуалы относились к группе «ситуационистов». Они предложили новую организацию городского пространства и считали, что современная им архитектура сковывает человека как физически, так и идеологически. Ими были введены понятия «психогеографический рельеф города» и «городской ландшафт». Они понимали психогеографический рельеф города как движение постоянных потоков с фиксированными фокусными точками, ограничивающими доступ к определенным городским зонам. Один из исследователей психогеографии города Ги Дебор предложил объединить два фактора, организующих городское пространство: «мягкий», который состоит из потоков света, звуков, времени, идей и «жесткий», включающий архитектурные элементы города.

Исследователями психологии городского пространство было введено и понятие образа города. Образ города это репрезентация городского пространства (природного, социального, культурного, информационного и т.д.) в сознании индивида или социальной группы. Образы имажинальны, разномодальны по своему происхождению. Образ города может быть результатом непосредственного восприятия, воспоминанием, или он может быть сформирован на основе представления об этом городе. Образ города - это сложная система значений, связанная со средой, в которой он существует, и представляет собой пространственную модель или когнитивную карту, переплетенную сетью личностных смыслов. Этот образ может быть индивидуальным, присущим определенной личности, либо коллективным, сформированным определенной группой лиц.

Так, коллективный образ города сочетает в себе элементы образов, свойственных каждому из тех, кто внес в него свой вклад. Этот образ сочетает в себе систему социальных представлений, а значит, воспринимается как среда обитания и пространства для жизнедеятельности. Городские образы могут быть фрагментарны [6]. Фрагменты городской среды - это «предметы в возможности», для которых нужна идентификация, т.е. подведение нового переживания под уже известную схему. Феноменологически это значит, что мы идентифицируем предметы не потому, что они таковы, а потому, что наш опыт типически сконструирован так, что мы можем применить знакомые представления к новым ситуациям [1]. Образ города - семантическая конструкция (система знаков), задающая схемы восприятия (на сенсорно-информационном уровне), на базе которой отбираются значимые аспекты и предметы городской жизни [1].

Эвристический смысл изучения образа города - рассмотрение его как фактора поведения. Это фактор особенного рода, особенность его в том, что он не обладает жёстко детерминистским характером и оказывает опосредованное влияние на поведение личности. Образ формируется в определённой степени спонтанно из хаоса воспоминаний, но, кристаллизуясь, создаёт некую очевидность как осознание порядка, как интенцию на определённый стиль жизни, на систе- 
му определённых значений и смыслов [2]. Так, положительный образ города, формируемый у туристов, привлекает их к посещению и изучению данного города, побуждает бродить по его улицам, паркам, музеям, а отрицательный образ отталкивает потенциальных туристов от ознакомления с данным городом.

Что касается самих горожан, то положительный образ города благоприятно влияет на их психологию, что формирует желание как можно больше времени находиться в городской среде, посещать его достопримечательности и проводить досуг в городских рекреационных территориях. Отрицательный образ города гонит его жителей из города, вызывает постоянное желание поменять место жительства, отдыхать только за его пределами. Для горожан, независимо от позитивного или негативного образа, город является постоянным местом их жизнедеятельности и обитания.

Рассматривая город как место жизни людей, мы можем выделить три особенности: во-первых, особый рисунок поведения жителей в городской [1]; во-вторых, особая роль соседства горожан в условиях крупного города, обусловливающая анонимность каждого, и особенности внутригородских миграций, связанных с поведением человека, ежедневно перемещающегося на большие расстояния и затрачивающего много времени на это перемещение [2]; в-третьих, это особая материальная среда большого города, учитывающая психику человека.

По мнению некоторых ученых, исследующих психгеографию города, в нём меняется характер взаимодействия людей по сравнению с сельской местностью, ввиду того, что смена технологических основ общественного развития в сочетании с быстрым ростом городского населения меняет и сам характер взаимодействия людей. Это объясняется тем, что, живя в сельской местности, индивид общается с несколькими десятками или сотнями людей, а в городе он сталкивается с многими тысячами, и это увеличивает его раздражительность, способствуя росту агрессивности.

Психолог Теннис считает, что в городе возникает новый особый городской образ жизни и что сельский образ жизни существует только в рамках сельской общины, и его не может быть в рамках города. Городской образ жизни отличается от сельского тем, что теплые дружеские соседские отношения замещаются формальными, ограниченными, случайными, обезличенными и узкоспециализированными отношениями [5]. Городской образ жизни характерен тем, что общество становится менее дружелюбным, приобретая такие особенности, как: легкую интеграцию в общественное пространство любого нового жителя, малую зависимость каждого от мнения других и, как следствие, большую свободу личности и ее анонимность.

Особенности городского и сельского образа жизни исследовались психологом Зиммелем, который отмечал значительные различия в темпах жизни городского и сельского жителя. Он утверждал, что характер поведения в жизни традиционного сельского сообщества поддерживается бессознательно и по привычке, а в жизни городского - наоборот, оказывается постоянное материальное воздействие различных требований городской сре- 
ды и сильных раздражителей, влияющих на нервную систему. Одним из таких раздражителей в городе служит транспорт. Многие жители селятся на улицах со средним движением, из-за приемлемых условий жизни и высокого качества окружающей среды. Однако со временем они высказывают свое недовольство, так как тихая улочка постепенно превращается в значительную транспортную магистраль. Жители тихого квартала изначально более требовательны к качеству окружающей среды, чем жители, проживающие в районах с интенсивным движением, и разочарование их становится более сильным.

Большое влияние на поведение человека в городе оказывает высокий уровень шума, который вызывает раздражение и стремление отдалиться от социальной жизни местного сообщества. Однако, согласно исследованиям об измерении шума до и после открытия движения транспорта по магистрали, в установках людей происходит мало изменений [3]. А из проведенных исследований жителей, сталкивающихся с трудностями, вызываемыми транспортом или близостью аэродрома, выяснилось, что они принимали это как данность, ввиду невозможности удалить или повлиять на источник стресса.

Также на поведение горожан оказывает влияние высокая плотность населения. В течение длительного времени считалось, что оно ведет к болезням. Большинство исследователей указывают на существование проблем, связанных с высокой плотностью населения. Так, в мегаполисах жители испытывают сильные стрессы, связанные с проживанием в высотных домах. Именно в таких домах очень распространен вандализм, жестокость, грабежи, изнасилование и другие социальные проблемы [4]. Психолог Ньюман утверждает, что высокий уровень преступности может быть связан и с особенностью планировки таких зданий, в которых люди лишены права владения территориями, прилегающими к их жилищам, то есть пространством за пределами своей квартиры, которое считается общественным. Соответственно с увеличением высоты зданий возрастает и доля преступлений.

Bсе эти антисоциальные проявления провоцируют стрессы и дистрессы горожан. В городе возникает ряд стрессоров. Под стрессорами понимаются факторы, вызывающие состояние стресса. Эти стрессы часто нивелируются под воздействием адаптационных механизмов. Жители крупных городов могут адаптироваться к повышенным уровням шума, запыленности, загрязненности, то есть к факторам, каждый из которых может оказывать прямое воздействие на качество жизни.

Тем не менее крупный город может быть очень приятным местом для проживания, местом, пребывание в котором повышает общий тонус, и являющимся источником вдохновения и творчества, предоставляющим отличные возможности для раскрытия личности [2]. Как считают исследователи городов, такие, как Г. Гибсон, Дж. Голд, К. Линч и другие, городские пространства оказывают большое влияние на состояние визуального восприятия, которое может формировать как позитивное, так и негативное восприятие, что влияет на психологию горожан и на формирование образа города визуалами [4]. 
Многоэтажная застройка, колодцеобразные дворы, узкие пространства между зданиями отрицательно влияют на сам характер зрительного восприятия. Физиологи отмечают, что зрительное восприятие практически перестает при этом функционировать, что снижает возможности визуализации. В случае экопозитивного восприятия городской среды (парков, городских ансамблей, отдельно стоящих красивых зданий, сочетания архитектурной среды с гидрологическими объектами и «зелёной» архитектуры) у жителей и туристов формируется позитивный образ города. Таким образом, эта среда благотворно влияет на психику человека. И этот человек инстинктивно стремится отдыхать в рекреационных условиях, близких к условиям своего города.

Психологи констатируют, что во многих городах выявлено большое количество гомогенных и агрессивных полей, которые угнетают психику человека и понуждают работать зрение в неэкономном режиме, что, в свою очередь, приводит к эмоциональному дискомфорту. Однообразие колористики ряда городов, с преобладанием серых и тёмных оттенков зданий способствует негативному восприятию городской среды и резкому отличию городской визуальной среды от естественной. Визуальную среду существенным образом изменили транспортные средства. Так, водитель автомобиля получает дополнительную зрительную нагрузку, когда смотрит на перемещающиеся объекты, убегающий асфальт, мелькающие деревья, столбы, дома, несущийся навстречу транспорт и сигнальные огни.

Комфортные видимые среды, для которых характерно большое раз- нообразие элементов в окружающем пространстве, положительно влияют на психофизиологическое состояние человека, так как в таких средах все механизмы зрения работают в предпочтительном режиме. Всегда находятся люди, свято верящие в то, что проживание в городе, вне всяких сомнений, является благом или по крайней мере предоставляет максимум возможностей для всестороннего развития способностей человека, тогда как другие относятся отрицательно ко всему, что связано с городом.

Отношение к городу в разное время и в разных культурных традициях складывалось по-разному. Город и сельская местность воспринимались полными антиподами. Город обрекал людей на неестественное существование, а жизнь в деревне обеспечивала близость к природе, а значит, к Богу, следовательно, способствовала достижению морального и духовного здоровья. Идиллические образы деревни противостояли образу города. Складывалось мнение, что город извращает фундаментальные ценности и обрекает людей на тяжёлую жизнь, полную страданий и перегрузок. В то же время стали слышны немногочисленные голоса тех, по мнению которых, город обладает рядом неотъемлемых особенностей, чрезвычайно благоприятных для развития личности.

Критики города говорили о больших сложностях в городской ориентации. Для того чтобы успешно ориентироваться, необходимо обладать двумя близкими по функциям способностями: умением определять направление и расстояние. Из имеющихся работ по изучению городской среды следует, что основными факторами, влияющи- 
ми на эффективность процесса ориентации, являются: возраст, степень знакомства с данным городом и культурные особенности человека.

На восприятие городских расстояний колоссальное влияние оказывает центростремительное или центробежное размещение объекта внутри города по отношению к собственной локации человека. На особенности ориентации большое влияние оказывает притягательность городских объектов, до которых определяется расстояние. Точность определения расстояний зависит от степени знакомства с данным городом. Восприятие расстояний зависит также от извилистости пути, включающей множество поворотов. Извилистые дороги кажутся более длинными, чем дороги такой же длины, напрямую соединяющие два городских объекта.

Человек видит город, как некоторую последовательность следующих друг за другом образов, которые в процессе умственной деятельности организуются так, чтобы результатом восприятия были яркие или эмоционально окрашенные картины города. Это явление известно под названием «сериальное зрение». Так, прямая ровная дорога, уходящая вдаль, имеет слабое эмоциональное воздействие. Картина зрительных впечатлений города слагается из двух компонентов - наблюдаемых и формируемых видов. Даже следуя по одному и тому же пути, пешеход и водитель видят окружающий мир поразному, вследствие неодинаковости углов зрения, под которыми воспринимаются объекты, а также разницы в продолжительности времени их обозрения, связанным с разницей скоростей передвижения. Изолированность ограниченного пространства автомо- биля отделяет человека от запахов и звуков внешней среды и приводит к тому, что большую часть информации водитель получает при помощи зрения.

В психогеографии города большое внимание уделяется эстетической притягательности различных городских «мест», под которыми понимаются городские ландшафты, вызывающие особое чувство притяжения как горожан, так и людей, посещающих данный город. Такие ландшафты, как правило, связаны с сочетанием архитектурных памятников, сооружений, ажурных арок, мостов с голубой архитектурой города: реками, озёрами, прудами, фонтанами и элементами зелёной архитектуры: парками, садами, бульварами, озеленёнными улицами, цветочными насаждениями, клумбами, ампельными растениями и др. Эти места наиболее благоприятно воздействуют на психику человека [8].

Другими местами притяжения населения являются шопинг-центры с красиво оформленными витринами и выдвинутыми на улицу объектами общественного питания. При этом покупатели предпочитают посещать магазины в шаговой доступности, а также магазины, в инфраструктуре которых расположены стоянки для различных видов транспорта. Покупатели обычно пользуются знакомыми магазинами, а внутри магазинов их раздражает деятельность мерчендайзеров, переставляющих товары и продукты на другие, незнакомые места.

Целый ряд географических работ посвящен исследованию существующих в сознании людей представлений о возможных местах совершения тех или иных покупок. Так, Бреннан ука- 
зывает на различия в предпочтениях индивидов в территориальном размещении различных шопинг-центров, а Брюс и Даунс посвятили свои работы исследованию притягательности различных торговых точек и центров. А Лентнек уделяет внимание предпочтениям покупателей при посещении шопинг-центов, связанных с уровнем их финансового благополучия [8].

В восприятии городского визуального ландшафта оказываются объединены разнородные характеристики объекта. Психологические установки, в которые вовлечён воспринимаемый элемент городской среды, его культурный статус, эмоциональное состояние, оказывают решительное влияние на оценку и формирование образа города. Эти ученые связывают оценку и формирование образа городской жизни с психологическими установками, в которые вовлечён горожанин в процессе восприятия городской среды.

На восприятие городской предметно-пространственной среды оказывает влияние также ориентация человека в городском пространстве в направлениях: вперед, назад, вправо, влево, вниз, вверх. Большую роль играет и персональное пространство, окружающее человека: человек в толпе, человек на открытом городском пространстве. Под персональным в науке понимается окружающая человека зона, вторжение в которую вызывает различные негативные психические реакции.

Образы осознаваемого городского пространства обязательно несут на себе печать различных процессов, протекающих в окружающей городской среде, то есть, глядя на элементы городского пространства, мы воспринимаем внутреннюю информацию о предметах и явлениях видимой картины города. Городской ландшафт воспринимается через его живые и архитектурные компоненты. Визуальное восприятие городских пространственных измерений для всех людей одинаково, но воспринимается ими по-разному. Так, зрению свойственно преуменьшение пространственных величин, при этом горизонтальные городские объекты воспринимаются с большей степенью ошибок, а вертикальные - с меньшей.

Под фрактальностью и фрактальными связями в науке понимаются подобия и самоподобия между явлениями, предметами и фактами. Одна из исследователей фрактального анализа города Е.В. Николаева понимает его как выявление повторяющихся самоподобных геометрических или социокультурных паттернов и определение их типов. Любой самоподобный фрагмент фрактальной конструкции в городе репрезентирует целое, "разворачивая» из себя весь комплекс значений и форм, которые присущи любому фракталу, как целостному явлению.

При фрактальном анализе городской застройки можно выделить несколько способов фрактального подобия: линейное, которое по способу построения называют геометрическим. В городе это подобие наиболее очевидно, например, пятиэтажные здания, выстроенные в эпоху Хрущёва, а также любые здания, построенные в форме вертикальных или горизонтальных параллелепипедов. Другой формой фракталов является нелинейное (алгебраическое) подобие, которое выявляется только с помощью математического аппарата. Этот вид фрактала прослеживается в виде планов 
городской застройки уового времени, например, театры, концертные залы, гипермаркеты, молодежные центры, спортивные сооружения и др. [8]

Фрактальность по-разному влияет на психологию человека: наличие фрактальных складских помещений, серых "хрущёвских" пятиэтажек угнетает психику человеку, усиливает его агрессивность, вселяет чувство безнадежности, что может способствовать антисоциальным проявлениям горожан. Даже новейшее градостроительство, основанное на ультрасовременном матричном подходе, изгоняет человека из города на расстояние часа езды на автомобиле. Причиной этого бегства из города служит фрактальное однообразие новых построек. В результате того, что в современных городах представлены постройки различных исторических эпох и отражены фрактальные особенности других городов мира, в них формируется постмодернистский хаос, образующий исторический фрактал локальной культуры. Что также способствует желанию горожанина отдыхать в условиях естественной природы, вдали от городских поселений [4].

Рассмотрим влияние экологической и географической среды города на психологию. В современных городах возникает своеобразная экологическая среда. На психику жителя города оказывают влияние такие экологические факторы, как: загрязнение окружающей среды, дефицит питьевой воды, удаленность от лесопарковых территорий, асфальтовое покрытие улиц и площадей, кислотные и радиоактивные осадки, шумовое и электромагнитное воздействие и др. Каждый такой фактор влияет на психику чело- века как изолированно, так и во взаимодействии с другими. В современных городах экологические проблемы негативно влияют на здоровье человека. Так, в крупных городах отмечены такие проблемы здоровья населения, как: болезни органов кровообращения, неврозы, снижение остроты зрения, травматизм и др. Известно, что в крупном городе человек очень быстро утомляется, что снижает его работоспособность и отрицательно влияет на его поведение. Длительные переезды от работы к дому, шум транспорта, ускоренный ритм жизни отнимают у горожан много сил. Особенно это заметно к концу рабочего дня, к концу недели и месяца.

Большое влияние на социально-психологические отношения, психологию общения, социальные аспекты групповых психических процессов оказывает городской стресс, являющийся одной из причин патологии городской жизни. Для современной науки характерна пессимистическая, негативная оценка роли городской среды и ее влияние на образование стрессового фактора у горожан [8]. В городских районах, заселенных социальными низами общества, преобладает негативное восприятие города и стремление вырваться из городских «джунглей» на природу. Из этого некоторые психологи делают вывод о том, что поведением человека управляет некий врожденный принцип территориальности, что причина отклоняющегося поведения - неудовлетворенная потребность человека владеть индивидуальной территорией. Однако первичной причиной является здесь, конечно, не только концентрация населения, но и общественное неравенство. 
Все же, понимая важную роль социально-экономических факторов, пессимистически настроенные психологи признают тот факт, что высокая плотность населения выступает в качестве самостоятельного фактора, вызывающего возникновение патологий различного типа. Анализируя статистические данные, можно прийти к выводу, что распространение патологий в различных городах и городских районах соотносятся с динамикой изменения плотности населения. Однако при этом не учитываются социальные факторы, которые говорят, что главной причиной городского стресса является не скученность населения, а социальные проблемы городских окраин, в которых проживают различные этнические меньшинства, обделённые социальными правами. Другие психологи отрицают роль перенаселённости городов в развитии патологий и психологических стрессов, подчёркивая позитивные аспекты высокой плотности как условия расширения человеческих контактов и интенсификации человеческого общения [3].

Понятия «окружающая среда», «городская среда» в разных их модификациях в последнее время стали очень распространенными и приобрели значение ключевых. Возрастающее внимание к изучению проблем среды - характерное проявление экологизации и гуманизации современной науки.

Общая тенденция развития и роста городов - прогрессирующее ухудшение в них условий жизни. Одна из величайших трагедий городов в том, что, будучи высшим достижением человеческой цивилизации, они становятся не только неудобными, но и в значительной степени опасными для жизни, даже для жизни будущих поколений. Экологическое неблагополучие городов стало острейшей глобальной проблемой, требующей скорейшего решения.

Благодаря свойствам своей среды, города становятся «творческой ораторией» человечества: «Качество городской среды в конечном счете определяется способностью городов, с одной стороны, быть фокусами творческих сил общества, реализовывать, концентрировать в себе творческий потенциал и, с другой - создавать необходимые условия для приобщения каждой личности к различным формам жизни города»

Можно говорить о двух взаимосвязанных сторонах городской среды. Она выступает как комплекс условий жизни людей, «потребляющих» среду, удовлетворяющих свои потребности, что находится в прямой зависимости от качества среды. Одновременно городская среда является совокупностью условий для творческой деятельности, формирующей новые направления в науке, искусстве, культуре и т.д.

Кардинальное решение проблемы справедливо виделось на пути преобразования существующего расселения, отказа от тех форм расселения - крупнейших городов и гигантских агломераций, в которых урбанистический пресс на природу и человека оказался невыносимым.

Состояние компонентов природы важный индикатор состояния и качества городской среды. Находясь под антропогенным прессом, подвергаясь многообразным нагрузкам, природа способна восстанавливаться, спасая тем самым себя и защищая человека. Город - ареал глубоко измененной 
природы, особая экосистема. Населения и города можно уподобить вулканам, извергающим на собственную поверхность и окружающие территории огромное количество газообразных, жидких и твердых веществ

Городами ближайшего будущего являются «экогорода» (экополисы, экограды, экосити). Идею экограда ввел американский эколог Ричард Реджистер в 1978 г. Под этим термином он понимал экологически чистый город. В настоящее время это понятие трактуется гораздо шире. Многие ученые считают, что экогород должен самообеспечиваться продовольствием и энергией, при этом жилая зона должна быть минимальной.

По мнению русского ученого A.Н. Тетеора, экосити строится на принципах экологичности и находится в равновесии с природой. Минимально загрязняющий природу и пронизанный зелеными коридорами с экологичными зданиями, экологизацией деятельности людей, высоким качеством жизни, системой экологического образования и воспитания и вовлечения всех горожан в процесс экологизации их жизнедеятельности. Н.В. Русонд считает, что эко-город служит административной единицей, имеющей экоэффективную и экономически производительную промышленность, ответственную и социально гармоничную культуру и красивый функциональный ландшафт.

Основными принципами функционирования экогорода многие ученые считают: замкнутый цикл промышленных предприятий; применение энергосберегающих технологий; переработку бытовых отходов; использование экологичного автотранспорта; малоэтажное строительство; использование подземного пространства для устройства складов, гаражей, стоянок; озеленение вертикальных и горизонтальных поверхностей зданий и сооружений (кровли-газоны, столбы освещения, стены-газоны, озеленённые ограды); проектирование квартир с выходами на зимние сады, веранды, уютно озеленённые дворы; участие каждого жителя города в проектировании, строительстве и отделке экодома. Создание экоцентра для экологического образования и воспитания.

Одной из целей создания эко-города (зелёный экосити) может быть сохранение городской природной среды, увеличение её разнообразия, чтобы она была более дружественна для городских жителей.

Другой вид экосити - здоровые города, имеют целью своего создания устойчивое развитие, признающее право будущих поколений. А задачи обеспечения здорового образа жизни и её высокого качества в условиях экогорода.

В Европейском союзе существует шесть эко-городов: Мальмё (Швеция), Дублин (Ирландия), Таллин (Эстония), Хиллерот (Дания), Гамбург (Германия), Аугустенбог (Дания). Эко-города существуют в Северной Америке, Австралии. Экогород планируется построить южнее города Москвы [7].

С точки зрения русских учёных, эко-города могут возникать как города-спутники, оптимальная величина которых может достигать трехсот тысяч жителей. Эти города могут соответствовать десяти признакам эко-города: наличие парков и парковых зон, создающих комфортную рекреационную среду; эффективно работающую 
систему общественного транспорта, функционирующую на альтернативных источниках топлива; наличие велосипедных дорожек и прокатных центов велосипедов; применение зеленых технологий при строительстве зданий и жилых домов; использование экологичных и экономичных энергосберегающих технологий (солнечные батареи, утеплители, ёмкости для сбора дождевой воды); утилизация бытовых отходов при сортировке мусора и наличие административных программ отсортировки мусорных отходов; переориентация старых строений под нужды города; разработка и внедрение экологических программ и инициатив на городском уровне; эффективное энергопотребление и энергосбережение; экообразование и эковоспитание горожан.

В каждом эко-городе должны осуществляться экологические приоритеты, то есть сохранение окружающей среды и снижение давления человека на природную среду внутри города.

В экологических городах социокультурные и экологические процессы влияют на характер восприятия этих процессов горожанами, так как образы восприятия городского пространства - это всегда некоторые социокультурные проекты. Так как городская среда - это хаос предметов, объектов, значений, масштабов и смыслов, личность из этого хаоса выбирает значимые для себя фрагменты и создает из них определенный порядок, свой локус пребывания, поэтому в экогороде создается особая атмосфера, комфортная для пребывания граждан, заложенная ещё в процессе проекти- рования экогорода, его строительства, его создания и функционирования. Кроме этого, архитекторы заботятся о психологическом удобстве жителей города - это, прежде всего, избегание планировочных и строительных форм, способных вызвать фобии горожан и подавление их психики. Отсутствие в городе высотных зданий и сооружений, узких улиц и переулков, дефицита зеленых насаждений и др. Малоэтажная застройка, наличие скверов, водных объектов (пруды, фонтаны), создание оригинальных архитектурных ансамблей и избегание серых и мрачных тонов в окраске зданий, сооружений способствуют созданию психологического комфорта горожан. В городе должны избегать наличие замкнутых, затемнённых пространств, провоцирующих страхи горожан.

В эко-городе вся городская застройка и отделка должна осуществляться экологически чистыми материалами. В городе необходимо избегать факторов, провоцирующих агрессию у жителей, при этом важно уделять внимание борьбе с различными видами загрязнения: шумовым, вибрационным, электромагнитным и др.

Таким образом, экологический город будущего будет способен снимать психологическое напряжение у его обитателей и становиться центром притяжения туристов. При этом промышленные районы города должны отделяться от спальных лесными массивами. Экологизация городского пространства будет способствовать формированию притяжения города для приезжих и созданию положительного образа. 


\section{ЛИТЕРАТУРА}

1. Валишин Ю.И. Краткий социальный географо-психологический словарь. М.: ООО «Дизайн студия Смирнов АРТ», 2017. 172 с.

2. Валишин Ю.И. Применение психогеографии при изучении географических сведений в начальной школе: учебно-методическое пособие. М.: ООО «Дизайн студия Смирнов АРТ», 2015. 43 c.

3. Ванейгем Р. Революция повседневной жизни (Трактат об умении жить для молодых поколений). М.: Гилея, 2005. 288 с.

4. Голд Д. Психология и география: основы поведенческой географии. М.: Прогресс, 1990. 304 c.

5. Караванова Л.Ж. Психология: учебное пособие для бакалавров. М.: ИТК Дашков и К., 2014. $264 \mathrm{c}$.

6. Линч К. Образ города. М., Стройиздат, 1982.328 с.

7. Сергеев И.В., Веретенникова И.И. Организация и финансирование инвестиций. М.: ЮНИТИ, 2009. 400 с.

8. Эллард К. Среда обитания (Как архитектура влияет на наше поведение и самочувствие). М.: Альпина Паблишер, 2016. 282 с.

\section{REFERENCES}

1. Valishin Yu.I. Kratkii sotsial'nyi geografo-psikhologicheskii slovar' [A brief geographical and social-psychological dictionary]. Moscow, OOO 'Dizain studiya Smirnov ART' Publ., 2017. $172 \mathrm{p}$.

2. Valishin Yu.I. Primenenie psikhogeografii pri izuchenii geograficheskikh svedenii v nachal'noi shkole [The use of psychogeography in the study of geographical information in elementary school]. Moscow, OOO ‘Dizain studiya Smirnov ART’ Publ., 2015. 43 p.

3. Vaneigem R. The revolution of everyday life. London., Rebel Press, 2005. 279 p.

4. Gold J.R. An introduction to behavioural geography. Oxford, Oxford University Press, 1900. $290 \mathrm{p}$.

5. Karavanova L.Zh. Psikhologiya [Psychology]. Moscow, ITK Dashkov i K Publ., 2014. 264 p.

6. Lynch K. The image of the city. Massachusetts., The MIT Press, 1960. 194 p.

7. Sergeev I.V., Veretennikova I.I. Organizatsiya i finansirovanie investitsii [Organization and financing of investments]. Moscow, YUNITI Publ., 2009. 400 p.

8. Ellard C. Places of the Heart: The Psychogeography of Everyday Life. New York, Bellevue Literary Press, 2015. 253 p.

\section{ИНФОРМАЦИЯ ОБ АВТОРЕ}

Валишин Юрий Иванович - кандидат педагогических наук, доцент, профессор кафедры экономической и социальной географии Московского государственного областного университета;

e-mail: fakul-geo@mgou.ru

\section{ИНФОРМАЦИЯ ОБ АВТОРЕ}

Yurii Valishin - PhD in Pedagogical Sciences, associate professor, professor of the Department of Economic and Social Geography at the Moscow Region State University;

e-mail: fakul-geo@mgou.ru 


\section{ПРАВИЛЬНАЯ ССЫЛКА}

Валишин Ю.И. Психогеография города // Вестник Московского государственного областного университета. Серия: Естественные науки. 2017. № 2. С. 29-41

DOI: $10.18384 / 2310-7189-2017-2-29-41$

\section{THE CORRECT REFERENCE TO ARTICLE}

Yu. Valishin. PSYCHOGEOGRAPHY OF THE CITY. In: Bulletin of Moscow Region State University, Series: Natural Sciences, 2017, no. 2, pp. 29-41.

DOI: $10.18384 / 2310-7189-2017-2-29-41$ 